\title{
EL CONCEPTO DE LIBERTAD EN EL HIMNO NACIONAL ARGENTINO
}

Susana Sarfson-Gleizer

doi.org/10.15452/SR.2020.20.0005

Universidad de Zaragoza

España

sarfson@unizar.es

\author{
Rodrigo Madrid Gómez \\ Real Academia de Bellas Artes de San Carlos de Valencia \\ España \\ rodrigomadridgomez@gmail.com
}

\begin{abstract}
Resumen. Desde 1813, la canción patriótica cuyo texto escrito por Vicente López y Planes, musicalizado por Blas Parera, y desde 1847 Himno Nacional Argentino, constituye una declaración de valores que asume la necesidad de articular el discurso patrio alrededor del concepto de libertad. Grito sagrado, en torno al cual se fue construyendo y desarrollando la nación, y resignificándose a lo largo del complejo devenir de la historia. Este artículo es una reflexión acerca de texto y música del Himno Nacional Argentino, valorando el constructo de libertad en su contexto simbólico, desde la época de su composición hasta su presencia en el siglo XXI. Hay que tener en cuenta que en la redacción inicial del texto imperaba una serie de conceptos y de símbolos comunes a las circunstancias de las independencias americanas, y que estos favorecieron la construcción de una identidad propia, en la que la libertad sería una orientación para la materialización de un ideal, que se refuerza en el canto cotidiano y grupal.
\end{abstract}

Palabras clave. Himno Nacional Argentino. Literatura argentina. Música argentina. Libertad.

Abstract. The Concept of Freedom in the Argentine National Anthem. Since 1813, the patriotic song, whose text was written by Vicente López y Planes and musicalized by Blas Parera and which became the Argentine National Anthem in 1847, has constituted a declaration of values that acknowledges the need to articulate the patriotic discourse around freedom. Sacred shout, around which the nation was built and articulated, and resigned throughout the complex becoming of history. This article is a reflection about the text and music of the Argentine National Anthem, valuing the idea of freedom in its symbolic context, from the time of its composition to its presence in the $21^{\text {st }}$ century. It should be borne in mind that a number of concepts and 
symbols common to the context of American independences prevailed in the initial wording of the text, and that these favoured the construction of an identity of their own, in which freedom would be an orientation for the materialisation of an ideal, which is reinforced in the daily and group singing.

Keywords. Argentine National Anthem. Argentine Literature. Argentine Music. Freedom. 


\section{Introducción}

Una invocación interpela al auditorio: iOíd, mortales, el grito sagrado: Libertad, libertad, libertad! Así comienza el texto de la que se llamó, en un principio, Marcha Patriótica.

En 1813, las Provincias Unidas del Río de la Plata estaban gobernadas por el Segundo Triunvirato, que convocó una Asamblea General Constituyente, formada por diputados enviados desde las distintas provincias que conformaban el territorio de lo que había sido el Virreinato del Río de la Plata entre 1776 y 1810. El objetivo de esta Asamblea General Constituyente era, justamente, dictar una Constitución para el nuevo Estado. Aunque no logró este propósito, la Asamblea de 1813 tuvo un rol importante en la conformación legislativa de una Argentina naciente, y estaba impregnada por los ideales revolucionarios y por la presencia de las logias masónicas, cuyos miembros tuvieron un protagonismo decisivo en los procesos que llevaron a las independencias de las naciones hispanoamericanas.

Justamente, la Asamblea de 1813 aprobó el uso de varios símbolos patrios: el Escudo Nacional Argentino, con una clara simbología de fraternidad, igualdad y libertad, está inspirado en un salvoconducto de la Revolución Francesa.

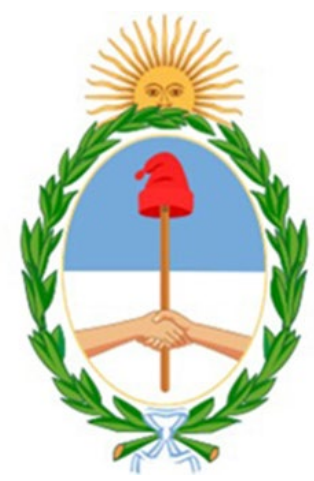

Imagen 1: Escudo Nacional Argentino actual

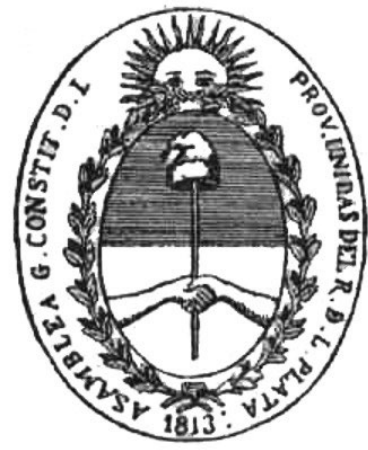

Sello de la Asamblea de 1813 (Buenos Aires)

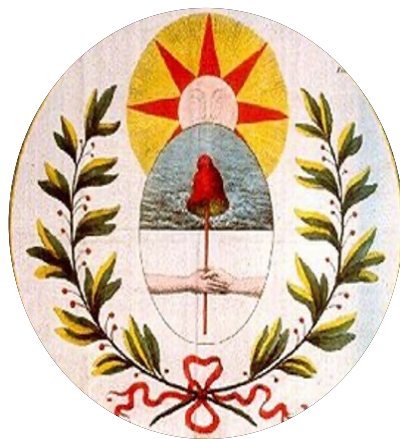

Salvoconducto Asamblea Legislativa 1790 (Francia)

Imagen 2: Sellos que inspiran el escudo argentino 


\section{La Marcha patriótica}

La Asamblea encargó la composición del Himno Nacional Argentino. La letra al escritor Vicente López y Planes: nacido en Buenos Aires en 1784, estudió en el Real Colegio de San Carlos (que actualmente es el Colegio Nacional Buenos Aires), y se doctoró en leyes en la Universidad San Francisco Xavier de Chuquisaca (hoy Sucre, Bolivia), es decir, su formación académica se realizó en instituciones fundadas por los jesuitas, que si bien habían sido expulsados, dejaron su inconfundible impronta intelectual, así como las estructuras e instituciones educativas más prestigiosas en la transición entre el Virreinato del Río de la Plata y el nuevo Estado. Precisamente, Vicente López era miembro de la Asamblea cuando recibió el encargo de escribir la Marcha Patriótica.

Vicente López había sido capitán del Regimiento de Patricios durante las Invasiones Inglesas, y eran conocidos sus poemas exaltando a la patria naciente, tales como «El triunfo argentino». Participó también en el Cabildo abierto de la Revolución de Mayo, así como en las subsiguientes acciones, como integrante del Ejército del Norte. Ocupó diversos cargos públicos en los años que siguieron a la Independencia de 1816: fue ministro de Bernardino Rivadavia, primer Presidente de las Provincias Unidas del Río de la Plata.

La música de esta Marcha Patriórica fue compuesta por Blas Parera, un compositor nacido en Murcia en 1776, aunque se formó musicalmente en Mataró, donde formó parte de la Capilla de Música del Colegio de Santa Anna. En 1797 se instala en la ciudad de Buenos Aires: allí fue organista de la Catedral Metropolitana, así como de las iglesias de San Nicolás, San Ignacio y La Merced (es decir, las que hoy son algunas de las más antiguas y tradicionales). No desconocía el aspecto musical del teatro, y así fue director de orquesta del Coliseo Provisional de Comedias de Buenos Aires, y tocaba el violín y el clave, instrumentos musicales de los que ofrecía lecciones privadas que le permitían complementar su exiguo emolumento como organista. En 1810 compuso melodías patrióticas en honor de la Revolución de Mayo. También se sabe que compuso un Canto a la memoria de Mariano Moreno en 1812, con texto de Fray Cayetano Rodríguez. La Asamblea de 1813 le encarga componer la música para la Marcha Patriótica, cuyo texto se debió a la pluma de Vicente López.

Esta Marcha Patriótica, devenida Himno Nacional, fue entonada en una reunión privada en la casa de María Sánchez de Thomson, una aristócrata y patriota porteña cuyo salón era lugar de debate de las vicisitudes políticas, así como punto de encuentro de la sociedad local: como era habitual en los salones románticos europeos, esas reuniones, herederas de los Ateneos de los nobles en las ciudades europeas y americanas durante el siglo anterior, eran un espacio de interpretaciones musicales, encuentros poéticos y debate político. En este espacio fue cantada por la anfitriona, acompañada al piano en un instrumento que hoy se conserva cuidadosamente en el Museo Histórico Nacional como reliquia de la nación naciente.

Además, al conmemorarse el 25 de mayo de 1813 la Revolución de Mayo de 1810, la Canción Nacional se presenta en el Teatro de Comedias, interpretada por un coro de 30 niños y una orquesta de 15 instrumentistas, todo bajo la dirección de Blas Parera.

La partitura original se perdió, y la que actualmente se interpreta es una reelaboración de Juan Pedro Esnaola (Buenos Aires, 1808-1878), quien preparó la partitura para piano y canto, así como la versión orquestal que fueron oficiales desde 1860.

El extenso texto del Himno Nacional Argentino refiere la exaltación de la independencia, pero, si bien en un principio resultó coherente con el contexto social, con el paso del tiempo se consideró agresivo hacia España y por tanto inadecuado como símbolo. En 1900 el entonces 


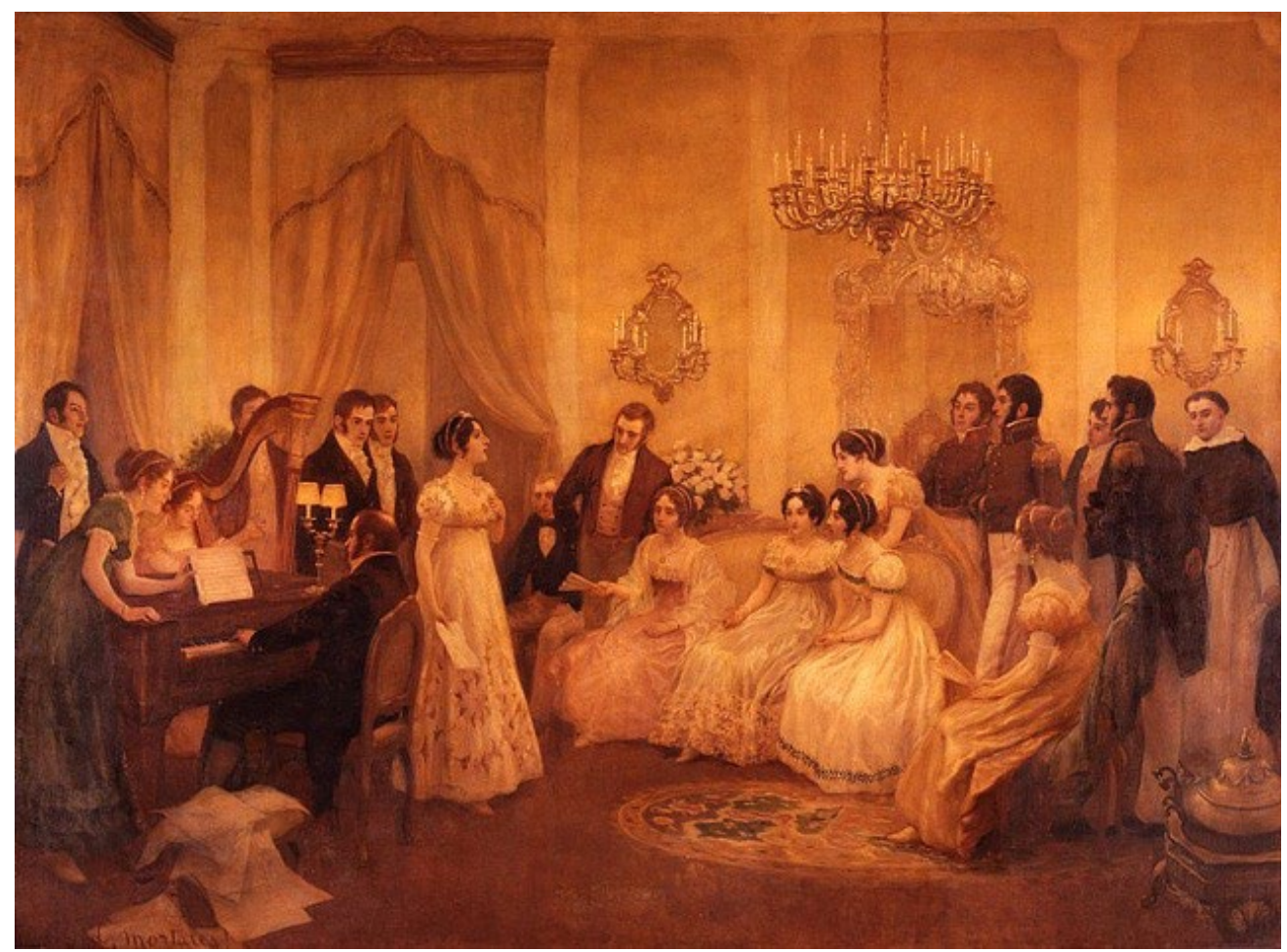

Imagen 3: Cuadro de Fray Pedro Subercaseaux Errázuriz (1880-1956), Instituto Nacional Sanmartiniano, Buenos Aires

Presidente de la República Argentina, Julio Argentino Roca, firma un documento según el cual se eliminan del canto todas las estrofas que pudieran ofender los sentimientos de los ciudadanos españoles, en especial teniendo en cuenta la gran cantidad de súbditos de España que residían ya entonces en territorio argentino.

El antiguo texto completo (siglo XIX) era extenso: dieciocho estrofas en las que se exalta vivamente una ensoñación marcial, donde no se exponen los horrores de la guerra sino los brillos del honor y de los linajes, así como la valentía de los pueblos americanos enfrentados a un invasor vilipendiado (cuestión que fue lamentada por su autor, décadas más tarde). Las alusiones mitológicas clásicas se enlazan con las de los Incas, en un intento de aunar imágenes de grandeza para sustentar los ideales que busca transmitir.

Pese a la extensión del texto original, lo incluimos a continuación: 
¡Oíd, mortales!, el grito sagrado: ¡libertad!, jlibertad!, jlibertad! Oíd el ruido de rotas cadenas ved en trono a la noble igualdad. Se levanta en la faz de la tierra una nueva gloriosa nación.

Coronada su sien de laureles, y a sus plantas rendido un león. (bis) Estribillo (con coro)

Sean eternos los laureles que supimos conseguir: (bis) coronados de gloria vivamos, o juremos con gloria morir. (tris) De los nuevos campeones los rostros Marte mismo parece animar. (bis) La grandeza se anida en sus pechos a su marcha todo hacen temblar. Se conmueven del Inca las tumbas, $y$ en sus huesos revive el ardor, lo que ve renovando a sus hijos de la Patria el antiguo esplendor. (bis) Estribillo (con coro)

Pero sierras y muros se sienten retumbar con horrible fragor. (bis) Todo el país se conturba por gritos de venganza, de guerra y furor. En los fieros tiranos la envidia escupió su pestífera hiel. (bis) Su estandarte sangriento levantan provocando a la lid más cruel. (bis). Estribillo (con coro) ¿No los veis sobre México y Quito arrojarse con saña tenaz? (bis) ¿Y cuál lloran, bañados en sangre Potosí, Cochabamba, y La Paz? ¿No los veis sobre el triste Caracas luto, y llanto, y muerte esparcir? ¿No los veis devorando cual fieras todo pueblo que logran rendir? (bis) Estribillo (con coro)

A vosotros se atreve argentinos el orgullo del vil invasor.

Vuestros campos ya pisa contando tantas glorias hollar vencedor. (bis)
Mas los bravos que unidos juraron su feliz libertad sostener a estos tigres sedientos de sangre fuertes pechos sabrán oponer. Estribillo (con coro)

El valiente argentino a las armas corre ardiendo con brío y valor: El clarín de la guerra, cual trueno en los campos del Sud resonó.

Buenos Aires se pone a la frente de los pueblos de la ínclita unión. Y con brazos robustos desgarran al ibérico altivo león.

Estribillo (con coro) San José, San Lorenzo, Suipacha, ambas Piedras, Salta, y Tucumán, la colonia y las mismas murallas, del tirano en la banda Oriental. (bis) Son letreros eternos que dicen: aquí el brazo argentino triunfó; aquí el fiero opresor de la Patria su cerviz orgullosa dobló. (bis) Estribillo (con coro) La victoria al guerrero argentino con sus alas brillantes cubrió. Y azorado a su vista el tirano con infamia a la fuga se dio. (bis) Sus banderas, sus armas, se rinden por trofeos a la libertad.

Y sobre alas de gloria alza el pueblo trono digno a su gran majestad.

Estribillo (con coro)

Desde un polo hasta el otro resuena de la fama el sonoro clarín. (bis) $Y$ de América el nombre enseñando les repite, mortales, oíd:

Ya su trono dignísimo abrieron, las Provincias Unidas del Sud. Y los libres del mundo responden al gran pueblo argentino salud. (bis) Estribillo (con coro). 
Dentro del contexto de la creación del texto poético, Rípodas Ardanaz (2014) destaca la situación de la ciudad de Buenos Aires, con una mayoritaria actividad mercantil, que busca, por tanto, la libertad de comercio, así como los cafés y salones privados de reunión de las élites como elementos que potencian los ideales plasmados en el texto original de Vicente López y Planes.

\title{
3. El Himno Nacional Argentino
}

A partir del Decreto del Presidente Roca, del extenso y bélico texto inicial decimonónico, en el siglo XX el Himno Nacional Argentino pasó a tener la primera estrofa, la última y el estribillo, de manera que permanece la exaltación de la libertad como ideal, eludiendo los sones guerreros y las confrontaciones con otros países.

Menéndez y Pelayo (1948: 334) observó que el texto se inspira en parte en un Canto de Guerra de los Asturianos, así como Carlos Vega (2005: 22) notó que también hay fragmentos traducidos o inspirados en la Marsellesa. Por otra parte, es el mismo autor del texto del Himno quien primero manifiesta su disgusto por una obra realizada quizás con tiempo insuficiente, tras el encargo recibido. Así, son muy interesantes las observaciones que el mismo Vicente López realiza en una carta que envía a su hijo en $1847^{1}$, donde dice:

\begin{abstract}
Te aseguro que no siento entera satisfacción, cuando tengo que revisar esta obra de mi juventud; quisiera corregir los muchos defectos que le encuentro, y que han pasado o inapercibidos, o respetados más bien por el prestigio. (...) Hay una estrofa que me disgusta sobremanera, y es la de «en los fieros tiranos la envidia/ escupió su pestífera hiel»; y lo peor es que no fui original, sino que traté de salir del paso, adoptando de las composiciones del mismo género que había leído, unas frases que me daban el concepto que trataba de expresar, pero sin la detención reflexiva que después he tenido para ver que ellas no me daban una pintura seria y noble y coordinada a la altura que había tomado desde el principio, y con que iba a acabar la obra, sino una que sacrificaba a la pasión de la época aquellas dotes. (...) Algunas veces me vienen tentaciones de corregir todos los defectos que reconozco y presentar el Himno reformado a la Legislatura. ¿Qué te parece?
\end{abstract}

Pero las tribulaciones de Vicente López han ido diluyéndose, en parte por el carácter casi sagrado que se asigna al Himno Nacional, como objeto de respeto especial e incuestionabilidad, como pórtico obligado de toda conmemoración argentina, sino también porque la extensión de tales estrofas lo hicieron poco práctico. Como se ha mencionado, ya en el año 1900 el entonces presidente Julio Argentino Roca ordena que el canto se limite a la primera y última esfrofas y el estribillo, y, en especial, para no ofender al pueblo español con las vehementes diatribas poéticas incluidas en su versión original.

Ahora bien, con respecto al concepto de Libertad referido en el texto del Himno, se trata de un concepto clave a lo largo del Romanticismo. La libertad entendida como necesidad del individuo (...) como marcha progresiva a la infinitud. El romántico se concibe a sí mismo como ser libre. Es la reivindicación del yo, la exaltación de quien se enfrenta solo a los elementos con la fuerza de su voluntad y de su espíritu. La ruptura de las estructuras poéticas y musicales del neoclasicismo es buscada por los románticos, cuyo ideal podría ser la figura de Beethoven, quien rompe las cadenas del servilismo musical. Para el artista, la emancipación de los mecenas para llegar a la libertad creadora, es lo que para los pueblos la emancipación de los reyes para llegar a la libertad nacional.

1 Archivo General de la Nación Argentina, Fondo Los López, AR-AGN.DE/LLOP documento № 2339, citada en Barcia (1982). 


\section{Conclusiones}

Antes del siglo XIX, las grandes obras musicales muchas veces habían sido compuestas específicamente para un espacio determinado: así, por ejemplo, Monteverdi compone el Orfeo para un palacio concreto en la ciudad de Mantua, Bach compone las cantatas para llenar el espacio arquitectónico de Santo Tomás de Leipzig: la obra musical (así como la obra pictórica o poética) no eran abstractas, sino pensadas para un espacio concreto y único. Sin embargo, a partir del siglo XIX, las obras musicales, concebidas como hijas del espíritu del artista y emanación del mismo, se interpretan en diversos espacios, no suelen tener una arquitectura prefigurada, es decir, comparten el mismo nivel de abstracción y de libertad al que aspira el compositor. Entonces, si la obra de arte en general puede despertar al contemplador, al interlocutor, y llevarlo a un mundo distinto, los himnos nacionales americanos trasladan al mortal hacia el elevado mundo de la libertad a través de esas obras literarias y musicales sacralizadas, simbólicas, que enmarcan toda conmemoración.

Resulta significativo el uso que el Himno Nacional Argentino ha tenido a lo largo del siglo XX como medio de aglutinación y de conformación de un ideal nacional. Especialmente en las primeras décadas del siglo, la población de la República Argentina fue conformándose de una forma singular: a la población local, formada por descendientes de los españoles y otros europeos (que conformaron fundamentalmente la burguesía decimonónica), así como personas provenientes de los pueblos originarios y afrodescendientes, se suman los nuevos inmigrantes, principalmente europeos pero también de todo el orbe (españoles, italianos, franceses, ingleses, alemanes, nórdicos, griegos, rusos, turcos, sirios, japoneses, etc.), que llegan con una gran diversidad de orígenes, lenguas y religiones. La escuela pública y los símbolos patrios pasan a ser un medio para integrar a los hijos de estos inmigrantes en una identidad común, argentina. En este contexto, tanto el Himno Nacional como otras canciones que idealizan las virtudes y cualidades del país van conformando, mediante el canto cotidiano al unísono, una voz común. La interpretación de estas canciones al comienzo de la jornada escolar funciona como un pórtico que separa la cotidianeidad profana de las familias de distintos orígenes, de la sacralidad escolar de la identidad común construida en torno a esa idealización. El Himno Nacional es, además, entonado los días de celebraciones patrias, que constituyen jornadas de asueto escolar, dedicados a la conmemoración de esos momentos fundacionales idealizados, y que requieren de un ritual específico.

Llama la atención que en el siglo XXI, el Himno Nacional al que nos referimos sigue aglutinando, aunque de diferente manera. En los partidos de fútbol, entonado con tosquedad, o en los momentos de graves incidentes políticos, como forma de protesta y unión. El Himno Nacional Argentino, como los himnos de las demás naciones americanas, fue creado como obra de arte y como símbolo de los pueblos, pero con su interpretación intenta transformar en sacro el espacio banal, a través de la entonación colectiva de las estrofas que buscan unir el espíritu de las gentes vinculadas por habitar un mismo terruño. 


\section{Bibliografía}

У ADAMOvsKY, Ezequiel (2012). «El color de la nación argentina. Conflictos y negociaciones por la definición de un ethnos nacional, de la crisis al Bicentenario».Jahrbuch für Geschichte Lateinamerikas - Anuario de Historia de America Latina, 49.1, pp. 343-364. https://doi.org/10.7767/jbla.2012.49.1.343

$\checkmark \quad$ BARCIA, Pedro Luis (1982, ed). La lira argentina o Colección de las piezas poéticas dadas a luz en Buenos Aires durante la guerra de su independencia. Buenos Aires: Academia Argentina de Letras.

$\checkmark$ BUCH, Esteban (2013). O juremos con gloria morir. Una historia del Himno Nacional Argentino, de la Asamblea del Año XIII a Charly García. Buenos Aires: Eterna Cadencia.

\ GUILlÉN, Cristina (2008). «Los rituales escolares en la escuela pública polimodal Argentina». Avá. Revista de Antropología, 12, pp. 137-154.

\ MENÉNDEZ PELAYo, Marcelino (1948). Historia de la poesía hispanoamericana. Ed. de Enrique Sánchez Reyes, T.2, Santander: CSIC.

\ PODERTI, Alicia (1999). «La nación imaginada: Trayectos ideológicos y ficcionales en el espacio andino». Anales Instituto Iberoamericano 2, pp. 107-122.

y RÍPODAS ARDANAz, Daisy (2014). «La "Marcha Patriótica" de Vicente López y Planes, espejo de sucesos y aspiraciones rioplatenses». ÉPOCAS - Revista de historia, 9, Buenos Aires: Universidad del Salvador, pp. 59-66.

$\checkmark$ TISSERA BRACAMONTI, Ana María (2002). «El Himno Nacional Argentino» en Morilla Ventura, Enriqueta, España y Argentina y sus relaciones literarias. Asociación española de estudios literarios hispanoamericanos, pp. 49-58.

$\checkmark$ VEgA, Carlos (2005, reed.). El Himno Nacional Argentino. Buenos Aires: Educa.

\section{Susana Sarfson-Gleizer}

Grupo de investigación Vestigium

Facultad de Ciencias Humanas y Educación de la Universidad de Zaragoza

Calle Vicente Carderera, 4

22003 HUESCA

España

\section{Rodrigo Madrid Gómez}

Académico de la Real Academia de Bellas Artes de San Carlos

Calle de Sant Pius V, 9

46010 VALENCIA

España 